\title{
Do problema do iconismo à ecologia da representação pictórica: indicações metodológicas para a análise do discurso visual Josć Bcnjamin Picado*
}

\section{RESUMO}

Buscamos avaliar a forte incidência que a discussāo sobre imagens nos estudos comunicacionais sofreu de um discurso fortemente marcado pela predominância de categorias próprias ao campo das teorias da linguagem; reconhecendo este movimento de incorporação dos saberes lingüisticos, para a avaliação das estruturas discursivas próprias aos icones visuais, propomos um viés alternativo de análise, fundado na compreensão da relação entre as estruturas de sentido próprias às representações visuais e aquilo que constitui uma matriz originariamente perceptiva dos fatos visuais.

\section{A B STRACT}

We intend to evaluate the strong influence of originally linguistic categorics in the debates about the discoursive status of images, specially in the communication reasearches; recognizing the movement that typifics this incorporation of linguistic knowledge in image-reading, we propose an alternative method of approaching visual icons, one which ould be founded in the proper comprehension of the relationships between the expressive procedures of image-making and the originally perceptual structures of visual understanding.

\footnotetext{
*PhD, professor do Programa de Pós-Craduação em Comunicaçāo e Cultura Contemporâneas da Universidade Federal da Bahia.
} 
"Mas não podemos negar que na própria natureza existem certos objetos e situações que costumamos chamar de pictóricos. O caráter pictórico parece ser inerente a eles, independentemente da concepção específica do modo de ver pictórico. Naturalmente, não existe um pictórico em si, e mesmo o assim chamado pictórico objetivo somente é pictórico para os olhos que assim o vêem; mas, por tudo isto, podemos destacar como uma categoria especial estes motivos, cujo caráter pictórico consiste em relações reais que podem ser demonstradas. São motivos nos quais cada forma está tão ligada a um contexto maior, que surge a impressão de um movimento continuo."

Heinrich Wölfflin, Conceitos Fundamentais da História de Arte (1915)

\section{A insignificância semiológica do iconismo: \\ a denotação como regime de base da significação analógica na fotografia}

Ao fim de seu clássico ensaio sobre a mensagem fotográfica, Roland Barthes explora a questão de uma hipotética insignificância fotográfica, como sendo um correlato das dificuldades metodológicas que se impunham à análise estrutural do discurso visual na fotografia: a fixação de um modelo de reduções (coincidente com o sistema das conotações) para as mensagens visuais acarretavam à semiologia visual as conhecidas dificuldades que, vistas em retrospectiva, caracterizaram os vícios teóricos implicados nesta vertente das disciplinas do sentido e da interpretação.

Deste modo, dado o fato de que o regime semiológico da representação visual coincidia, no mais das vezes, com a incidência de um sistema de significações segundo (associado, por sua vez, ao sentido puramente fático e denotacional da fotografia), o problema da interpretação dos ícones visuais invocava, do ponto de vista metodológico, que a matéria visual do discurso fotográfico estivesse necessariamente submetida às estruturas de compreensãò próprias ao discurso enunciativo.

Tomando o universo dos ícones fotográficos apenas como um material primeiro do discurso visual, aquilo que a abordagem semiológica pareceria legar ao tratamento da porção significante deste discurso (a saber, a própria matéria visual das mensagem fotográfica) era a de uma rigorosa insignificância (ao menos, do ponto de vista de sua dispośição para a análise dos materiais visuais): em contrapartida a uma tal possibilidade, Barthes reclama, ao final de seu ensaio, que o caráter histórico ou cultural dos códigos da conotação 
dever-se-ia exprimir como um principio estruturante, não apenas para o sistema das linguagens naturais, mas também para os regimes nos quais se enquadram discursos como o das representações visuais.

Assim sendo, dever-se-ia supor que a própria matéria significante das representações visuais estivesse submetida a estruturas de sentido que, se não chegariam a compor a unidade de um estrito código icônico (dada a dificuldade de se poder especificar as unidades discretas deste sistema, como no caso das linguas naturais), ainda assim se exprimiria como uma espécie de demarcação (cultural e temporalmente firmadas), de modo a que não abandonássemos as substâncias visuais a uma total impertinência, do ponto de vista da análise, por exemplo, sobre as formas de sua apreensão, na leitura ou na interpretação .

Isto posto, entretanto, as tarefas da semiologia não se deveriam supor esgotadas, no nivel deste reconhecimento de uma hipotética legibilidade da imagem (ou mesmo de outros materiais significantes), dados tais marcos metodológicos: pois, se um saber historicamente firmado pôde instruir a interpretação dos valores associados a certas ocorrências visuais, deveríamos supor que um fenômeno mais profundo da ordem da interpretação estabeleceuse, com força, aqui, a saber, o de que a própria percepção visual deve ser considerada como caso-limite (ou mesmo, inaugural) de interpretação.

Ao comentar este aspecto prolongado da teorização sobre a interpretação semiológica da mensagem fotográfica, Barthes se defronta com a necessidade de se contabilizar os aspectos propriamente percepcionais da conotação no discurso visual da fotografia: evidentemente, as preferências da semiologia se detêm no patamar daquelas explorações aos signos visuais que deixem entrever os elementos de reconhecimento histórico ou contextual, como parte de um léxico mais profundo (mas de origem em práticas concretas) desta atividade hermenêutica.

Nada diz que existam na fotografia, partes 'neutras', ou, ao menos, que a total insignificância da fotografia, de qualquer modo, excepcional; para resolver este problema, seria necessário, em primeiro lugar, elucidar completamente os mecanismos de leitura (no sentido físico, e não puramente semântico do termo), ou ainda, se assim se deseja, da percepção da fotografia; ora, sobre este ponto, não se sabe grande coisa: como lemos uma fotografia? O que percebemos? Em que ordem, segundo qual itinerário? Se, de acordo com Bruner e Piaget, não há percepção sem categorização imediata, a fotografia é verbalizada no momento mesmo em que é percebida; ou melhor ainda: ela não percebida, senão pela verbalização.' 
Ora, esta passagem do ensaio de Barthes, tão pouco lembrada entre seus principais comentadores e epígonos, expõe com brutal exuberância toda a ordem de tensões que parece atravessar o problema do firmamento categorial da interpretação das imagens, especialmente num campo como o da fotografia: de um lado (talvez o mais importante da questão), o fato de que, em sua dimensão de iconicidade (isto é, tomada em seu aspecto de objeto estético), o problema do sentido textual dos ícones deva ser correlacionado com as estruturas da sensibilidade, implicadas aqui, na condição de sistemas de signos; por outro lado (aquele que requer um certo exame crítico), o fato de que a suposta categorização de base do fenômeno perceptivo da imagem visual seja confundida com a redução das unidades icônicas à uma matriz linguística da compreensão do discurso visual.

$\mathrm{Na}$ síntese destes dois aspectos da questão, encontramos (uma vez guiados pela perspectiva barthesiana) algumas sugestões para um tratamento do iconismo visual que, nos pressupostos da escola semiológica, ainda permanecem acessando o sentido das mensagens estéticas por uma redução do sentido visual às estruturas da significação dos enunciados linguístcos.

Pretendemos apresentar, no espaço desta exploração, algumas considerações sobre o problema do tratamento analítico que a interpretação de imagens visuais pareceu suscitar, para o campo de estudos da comunicação: já reconhecemos anteriormente uma volumosa tradição de referências ao problema dos regimes de sentido próprios ao discurso visual, 202 especificadas no sotaque teórico das disciplinas semióticas. Ali, igualmente identificamos a predominância de um acento mais vocabular do que propriamente conceitual destas escolas teóricas, e as consequentes dificuldades de um acesso analiticamente rentável ao iconismo, fora do tom que as teorias semiológicas propiciaram, até aqui, para a discussão.

A nosso aviso, uma das conseqüências de um tratamento teoricamente mais adequado da questão do iconismo visual será necessariamente da ordem de uma geração de operadores metodológicos que permitam um tratamento efetivo dos regimes de significação do discurso visual. Ora, para que isto seja possível, é precisamente requerido das novas abordagens que se prenunciam no horizonte do debate entre as teorias estéticas e a história da arte, que estas sejam capazes de dar conta do problema da interpretação das imagens, numa espécie de chave analítica menos restritiva do que aquelas oferecidas, até aqui, pelas abordagens semióticas: as abordagens semiológicas sobre uma suposta linguagem das semelhanças gozou de certo prestígio, especialmente entre as ciências sociais, por propiciar às mesmas uma espécie de chave analitica aparentemente pregnante, para o entendimento de uma série considerável de fenômenos, associados às mensagens dos meios de comunicação. 
Vimos, entretanto, que, ao menos do ponto de vista teórico, deveríamos considerar mais detidamente o valor próprio às substâncias e formas visuais que entravam em jogo, na organização das mensagens visuais. Do ponto de vista metodológico, já avaliávamos que as abordagens semiológicas haviam se detido, de modo aparentemente precipitado, no patamar das reduções estruturais do discurso visual aos sistemas de significação que caracterizavam a linguagem enunciativa. Numa vaga similar a de certas correntes contemporâneas da filosofia da linguagem, considerávamos ser necessário avaliar criticamente as relações entre o significado da representação visual e o domínio de aplicação das descrições. ${ }^{2}$

Assim sendo, cremos que o problema da leitura das imagens vai requisitar decerto do campo comunicacional alguma atenção mais detida aos materiais significantes do iconismo visual, no percurso da explanação acerca dos regimes de base da compreensão do discurso visual, mas não de modo incondicionado: em termos, é igualmente necessário que estas abordagens possam vindicar seu espaço, não apenas na perspectiva da pertinência teórica das categorias implicadas nesse esforço (portanto mais afastadas do funcionamento destes discursos), mas sobretudo no escopo da análise de materiais concretos, que possa ser operada a partir da consideração sobre uma suposta autonomia do regime icônico das imagens, na sua relação com a ordem enunciativa do discurso.

Precisamente neste ponto, é que propomos um viés de interpretação do discurso visual na fotografia que seja capaz de incorporar ao acento comunicacional (predominantemente semiótico, em sua história) as contribuições que supomos encontrar nas teorias da representação pictórica, especialmente aquelas que se nutrem da influência das teorias da percepção. Na justificação da pertinência destas mesmas abordagens, encontramos dois aspectos principais de sua incorporação ao problema da interpretação das imagens: em primeiro lugar, a perspectiva pictorialista que avançamos (e que outros autores identificam com uma certa ecologia da representação pictórica) tem a propriedade de incorporar ao regime da compreensão do discurso visual os elementos propriamente icônicos da representação figurativa. Este procedimento renderá à análise dos materiais visuais o beneficio de um tratamento metodologicamente mais pregnante da significação analógica, certamente mais afastado da indesejável subordinação do discurso visual ao regime das conotações, e que caracteriza uma boa parte das abordagens semiológicas, por exemplo. ${ }^{3}$

Ora, o enfrentamento destas questões envolve, portanto, uma avaliação do estado da arte do debate sobre sistemas de significação, especialmente na medida em que esta parece acolher os fenômenos que tipificam uma suposta discursividade visual ou icônico-figurativa. Precisamente neste ponto da 
questão, parece-nos necessário avaliar, numa retrospectiva crítica, a grave incidência de um viés semioticamente restritivo ao tratamento da questão.

Antes disto, entretanto, devemos reconhecer um segundo aspecto da rentabilidade das abordagens que propomos lançar ao campo dos estudos sobre a interpretação das imagens. Ao supormos que um bom pedaço destas perspectivas de adordagem (por seu turno, inspiradas nas teorias da representação pictórica) enderecem o fenômeno pelo seu viés perceptual ou psicológico, poderíamos concluir que estas teorias não demarquem o problema da significação visual, naquilo que este se exprime enquanto sendo uma determinação temporal do mesmo.

Em termos, quando consideramos o argumento psicológico de base das teorias de Gombrich acerca do esquematismo da representação pictórica, não podemos supor que o mesmo esteja prescindido das conseqüências propriamente históricas de sua postulação mesma. Assim sendo, a idéia de que o esquematismo perceptivo rege as operações figurativas (seja no plano da criação ou da interpretação das obras visuais) não tem, para o autor de Art and Illusion, um significado especifico ou puramente formal, como se poderia supor. Ao contrário, a tese sobre a incidência de regimes de compreensão na caracterização das propriedades formais (ou icônicos) da figuração constitui um ponto para sua tese sobre a evolução histórica dos estilos pictóricos.

Acredito que só pela consideração desses aspectos psicológicos da criação e da decifração da imagem podemos chegar a uma compreensão dos problemas centrais da história da arte expostos por mim na Introdução. Por que a representação tem que ter uma história, por que a humanidade levou tanto tempo para chegar a uma reprodução plausivel dos efeitos visuais que criam a ilusão de semelhança e por que artistas como John Constable, que se empenharam em ser fiéis a sua visão, tiveram de admitir que nenhuma espécie de arte está livre das convenções, isto é, daquilo a que Constable chama de maneira."

Assim sendo, deveremos reconhecer que uma abordagem como a que anunciamos para o tratamento dos materiais visuais não é menos pregnante daqueles valores que, de alguma maneira, se cristalizaram para as perspectivas que predominaram, no campo da comunicação, lidando com o problema da significação analógica e do discurso visual. No campo da comunicação, podemos reconhecer uma clara dependência heurística que a questão da representação visual sofreu das abordagens que as disciplinas da linguagem e do sentido (muito especialmente, as teorias lingüísticas) aportaram, em termos de instrumentais de análise, especialmente no ambiente das ciências sociais: o fato de que propomos uma abordagem que possa, de algum modo, transcender a predominância dos enviezamentos teóricos, propiciados pelas abordagens semio-linguísticas, significa que temos que enfrentar este estado 
da questão, no modo como as teorias semiológicos no-la disponibilizaram até aqui.

Já pudemos observar em outras oportunidades que a recepção das abordagens semiológicas, no campo da pesquisa em comunicação foi claramente contemporânea do entusiasmo que as ciências sociais manifestaram em relação às ricas sugestões de análise que os instrumentais da lingüística e de alguns de seus ramos especificos (muito especialmente, a fonologia) aportavam para a abordagem das estruturas mais profundas (e necessariamente imotivadas) dos fatos sociais e humanos.

Na perspectiva destas teorias semiológicas, percebemos que o significado dos ícones visuais devesse estar de tal sorte instanciado pelas estruturas do discurso enunciativo que poderíamos prescindir, para fins de sua análise, de quaisquer considerações acerca de sua gênese material e plástica nas substâncias propriamente visuais das imagens: poderíamos identificar, nesta perspectiva que caracteriza o campo semiótico, uma predileção pela idéia de que a questão do iconismo deveria estar conformada a uma determinação do sentido visual, a partir de seu recurso a sistemas simbólicos determinados.

No percurso argumentativo de Barthes sobre uma pretensa semiologia das imagens, encontraremos alguns dos elementos mais caros à orientação que marcará a análise estrutural da imagem: em primeiro lugar, a própria concepção da relação entre imagem e significação, na qual o hipotético valor de sentido, como pura presença acusativa da referência na imagem (sobretudo a fotográfica), em nada concorre para qualquer discurso que busque firmar sua possivel significação; e, de fato, podemos identificar neste argumento (de resto, matricial para todas as correntes semióticas, não obstante o prosseguimento ou não da cartilha semio-estruturalista) a idéia central da impossibilidade última de um sistema de signos baseado em unidades analógicas.

Um contraponto especial destas assunções teóricas pode se encontrar incorporado nos argumentos negativos que Umberto Eco apresenta contra o predomínio das teses semiológicas acerca do discurso visual, na segunda parte de seu La Struttura Assente: as teses de Eco nos servirão para demonstrar que, se o significado icônico requer teoricamente a demarcação de um código, nada disto significa que tal primado deva se exercer, a partir de uma especificação teórica deste princípio; em termos, a tese pela qual concebemos que, no campo estético, devemos tomar certas manifestações como fenômenos de comunicação, não implica em que tais fenômenos se manifestem única e exclusivamente em termos de uma estrutura lingüistica de compreensão.

Veremos que esta posição de Eco sobre o estatuto de uma aproximação semiótica ao problema do iconismo atinge os preceitos da semiologia de Barthes numa instância que é a da própria natureza de constituição do signo analógico, uma vez supostas suas vinculações nativas com o objeto 
referencial: ora, a semiologia de Barthes se interrompera nesta questão (por supor que a iconicidade fotográfica constituísse uma questio facti), para estabelecer, em seguida, que o significado dos ícones requisitaria, de uma maneira ou de outra, o concurso de saberes linguisticamente organizados (seja sob a forma dos acervos simbólicos, narráveis através das culturas, seja por intermédio das estratégias discursivas, próprias ao campo retórico e narracional, e que convertem a imagem visual à ordem dos enunciados, das descrições e das ficções).

No nível de tais pressupostos sobre o problema da imitação da realidade na representação visual, as primeiras incursões semiológicas à imagem são claramente arrebatadas por uma concepção de um suposto realismo radical, originário da figuração icônica (especialmente no caso da fotografia), e que interditará Barthes (de modo permanente, até o final de sua obra) a um acesso mais sistemático sobre as formas de constituição de efeitos de sentido não hipostasiáveis à estrutura de base das línguas naturais.

Assim sendo, devemos olhar com suspeita este primeiro descarte analítico que a semiologia operara sobre o sentido propriamente icônico da imagem, para nos interrogarmos, em seguida sobre a suposta "natividade" da semelhança atribuída (sobretudo nas representações visuais) entre os ícones e suas réplicas: a prosseguirmos as lições da semiologia, não poderíamos enfrentar os ícones em sua própria gênese de sentido, pois, sobretudo quando consideramos o caso da fotografia, estas imagens se coligariam de tal modo 206 a seus objetos que sua significação teria muito mais uma valor deítico, de ostensão, do que propriamente de coordenação com um sistema semântico. ${ }^{5}$

Um primeiro aspecto, portanto, a se desmobilizar, no caminho de uma semiótica das mensagens visuais (e que incorporaria alguma reflexão sobre o significado do iconismo na representação) seria o de que a semelhança icônica se incorporaria, de algum modo, à estrutura última do discurso denotativo: pois esta é precisamente a operação metodológica de base pela qual a semiologia, ao menos na letra de Barthes, se privou de acessar o iconismo radical da imagem fotográfica, como um problema imanente ao saber semiológico. ${ }^{6}$

Entretanto, se pudéssemos enfrentar a questão do sentido da visualidade na representação (numa perspectiva ainda comunicacional, mas numa ordem mais pregnante àquilo que caracteriza uma fenomenologia do iconismo visual), certamente poderíamos descobrir os limites destas mesmas suposições semiológicas de uma constrição pelos códigos iconográficos, ou pelos operadores retóricos: a dimensão anunciada nos seus inícios, mas não cabalmente desenvolvida por Eco (a saber, a de uma dimensão propriamente estética da comunicação visual), ainda aguarda por uma exploração mais detida, sobretudo na perspectiva da geração de operadores metodológicos 
de base para a análise das imagens. Esperamos poder fornecer alguns dos elementos desta exploração, logo em seguida.

\section{Da representação à percepção da semelhança: um argumento psicológico sobre o discurso visual}

Ao assumir estas consequiências de uma critica à rentabilidade analítica de uma categoria semiótica como a do iconismo, as contenções que Umberto Eco oferece às tópicas semio-estruturalistas repercutem uma cara lição, originaria, por sua vez, de certos debates travados no campo das teorias e da história da arte. De modo não totalmente surpreendente, descohrimos que, também para certas vertentes das teorias estéticas (especialmente no último século), a questão do estatuto heurístico da interpretação de inagens parece causar certas perplexidade entre os teóricos, muitas delas semelhantes àquelas que caracterizam o esforço dos semiólogos em especificar, numa chave lingüistica, o estatuto da interpretação das imagens.

Numa boa medida, inclusive, perceberemos que as idéias que Eco introduz ao debate semiotico sobre o iconismo se nutrem fortemente do discurso que caracteriza estas tradições teóricas, por sua vez defrontadas com a questão de uma hipotética determinabilidade última do sentido para a experiência estética: assim sendo, as dificuldades que caracterizam o acesso analíticc das teorias semióticas aos materiais visuais refletem duas dificuldades principais: de um lado, aquelas que são específicas às disciplinas do sentido e da interpretação (uma vez defrontadas com a questão do discurso das imagens); mas, de igual modo, repercutem um padecimento categorial inerente ao próprio fenômeno (ou ao menos extensivo ao tratamento que outras disciplinas ofertaram para ele).

Se pudermos sumariar rapidamente estes supostos pontos de contato (assim como os eventuais limites) entre as teorias semióticas e as abordagens estéticas do discurso visual, talvez possamos sintetizar certas chaves analíticas para a aproximação ao núcleo do problema do significado icônico das imagens (sobretudo naquilo que este possa impregnar o viés propriamente comunicacional de sua postulação). Nossa hipótese é a de que o encontro dos problemas de uma estética formalista (vazada, por seu turno, de questões acerca da estrutura psicológica da experiência perceptiva) com o problema semiótico da determinação última de um sistema simbólico pode nos oferecer uma chave adequada ao trato analítico da comunicação visual, com a vantagem adicional de não isolar a discussão sobre as formas expressivas deste discurso no nível de sua caracterização enquanto estrutura lingüistica de compreensão.

Dentre os autores que Umberto Eco mobiliza com maior freqüência, na discussão acerca dos aspectos códicos e psicológicos envolvidos na caracterização de uma discursividade plástica e visual, nas artes e na comunicação contemporâneas, certamente encontraremos o nome de Ernest 
Gombrich, e a discussão que o tornou um clássico da história e da teoria da arte, acerca dos elementos estruturais de uma psicologia da representação figurativa, especialmente a partir de sua obra seminal, Art and Illusion: o diálogo entre Eco e Gombrich mobiliza sobretudo esta questão, essencial para a semiótica e para a história da arte, que é a da impressão da realidade, como um aspecto constitutivo da experiência do artístico, enquanto um meio de representação.

O tratamento isolado que possamos propiciar ao debate entre Eco e Gombrich revelará, a nosso aviso, um aspecto central de uma abordagem pictorialista dos significados visuais (e que instanciará, igualmente, os pontos de contato que propomos aqui entre as abordagens da semiótica, da estética e da história da arte): este ponto diz respeito às teses gombricheanas acerca do esquematismo último da representação pictórica, sendo a este propósito que Eco faz menção aos problemas centrais de Art and Illusion, sobretudo na segunda parte de La Strutura Assente, quando discute as relações entre o problema da representação de propriedades visuais do espaço, e o desenvolvimento de códigos propriamente estéticos (à luz dos exemplos visuais do pintor da escola naturalista inglesa John Constable, trazidos inicialmente por Gombrich).

Esse caráter convencional dos códigos imitativos foi muito bem sublinhado por Ernest Gombrich, no seu Arte e Ilusão, onde explica, por exemplo, o fenômeno que ocorreu a Constable ao elaborar uma nova técnica para representar a presença da luz na paisagem. O quadro de Constable, Wivanhoe Park, foi inspirado por uma poética da representação cientifica da realidade, e a nós nos parece puramente "fotográfico", com sua representação minuciosa das árvores, dos animais, da água e da luminosidade de uma nesga de prado batida de sol. Mas sabemos, também que sua técnica dos contrastes tonais, quando suas obras aparecem pela primeira vez, não era, absolutamente, encarada como uma forma de imitação das "reais" relações de luz, mas como um arbitrio bizarro. Constable inventara, portanto, um novo modo de pôr em código a nossa percepção da luz, e transcrevê-la na tela.?

Ainda sob este aspecto, a incorporação feita por Eco dos problemas da psicologia da representação pictórica em Gombrich implica ainda a questão das relações entre os códigos icônicos da figuração visual e um certo princípio de simplicidade das representações (cujas raízes podemos restituir às idéias de Arnheim acerca dos vínculos entre representação e percepção visual), ${ }^{8} \mathrm{e}$ que se define como uma espécie de estereotipia figurativa: a idéia da representação através de contornos simples (ainda que estes não fossem características originárias do objeto enquanto tal), atenderia a este princípio 
pelo qual o fenômeno da iconicidade faria igualmente apelo a um código de transcrição gráfica das propriedades visuais.

Este princípio da simplicidade não operaria apenas no nível de linguagens visuais altamente codificadas (como no caso das linguagens sinaléticas, que envolvem claramente uma dimensão icônica), mas teriam também um significado propriamente histórico, quando consideramos, por intermédio de Gombrich, o problema dos diferentes sistemas de representação visual: nestes mesmos sistemas, não poderíamos determinar que as representações constituissem apenas uma replicação de propriedades visuais, sem qualquer intermediação convencional e gráfica; assim, as imagens de animais de diferentes períodos históricos ilustraria a dificuldades de se enfrentar a significação destas representações visuais, a partir de uma assunção sobre compromissos originariamente ontológicos destas figurações.

No livro de Gombrich, existem exemplos memoráveis dessa aptidão. De Villard de Honnecourt - o arquiteto e desenhista do século XIII, que afirma copiar um leão do real e o reproduz segundo as mais óbvias convenções heráldicas da época (sua percepção do leão é condicionada pelos códigos icônicos em uso; ou os seus códigos de transcrição icônica não lhe permitem transcrever diversamente a percepção; e provavelmente está ele tão habituado aos seus próprios códigos que acredita estar. transcrevendo suas percepções do modo mais adequado) - a Dürer; que representa um rinoceronte recoberto de escamas $e$ lâminas imbricadas, imagem esta que permanece constante pelo menos durante dois séculos.

Este debate entre ambos se prolonga ainda, para envolver, no percurso semiótico de Umberto Eco, a posição que ele assumirá, a seguir, no debate acerca do estatuto teórico do iconismo, especialmente quando este se aprofunda no interior das teorias semiótica: quando procura matizar ainda mais sua preferência por uma visão convencionalista, Eco se mantém incorporando certas outras questões de Gombrich (como, por exemplo, a das distinções entre a dimensão morfológica e funcional nas representações visuais, a partir de seu ensaio clássico, "Meditations on a Hobby Horse").

Gombrich, em seu ensaio sobre um cavalinho de pau (que, na sua forma mais elementar, é um cabo de vassoura que a criança utiliza, como se fora um cavalo), observa que a relação de presumida iconicidade não está baseada em qualquer similaridade formal outra, que não a de um sentido vago, no qual o cavalo possui uma dimensão linear, que é uma propriedade pertinente (um sema de recognição) que pode ser igualmente encontrado no cavalo. De fato, o único aspecto que o cabo possui 
em comum com o cavalo real é que ele pode ser montado: assim, a criança tornou pertinente ou emergente uma das funções permitas pelo cavalo - e isto na base de suas próprias motivações fisicas ou psicológicas. ${ }^{10}$

O próprio Gombrich, por seu turno, também intervém no debate, reconhecendo os vocabulários da semiótica, incorporando-os e problematizando-os, na perspectiva de seu próprio projeto de uma história da arte informada por uma visão psicológica dos fenômenos figurativos: em seu caso, os problemas que convocam uma aproximação da semiótica á história da arte dizem respeito aos aspectos informacionais da imagem figurativa (que, não raro, sobretudo no campo semiótico, confundem a questão estética da representação visual com o problema lingüístico das descrições), e a dimensão psicológica e simbólica que envolve sua estruturação.

O problema central que motiva Gombrich a se interrogar sobre o lugar de uma abordagem psicologicamente orientada acerca da representação visual diz respeito a uma certa imediaticidade de nossas respostas a determinados aspectos da figuração: interrogando-se, por exemplo, acerca da iconicidade própria à arte de produzir mapas, Gombrich reconhece que as abordagens semióticas gozaram de um evidente privilégio no modo de acessar o fenômeno, ao menos naquilo que é próprio destas teorias; mas, ao observar que estas mesmas teorias parecem recepcionar, de maneira algo irrefletida, problemas filosóficos muito antigos (como o da distinção platônica entre semelhanças 210 "convencionais" e "naturais"), acabam por ficar interditadas a uma consideração mais detida, por exemplo, sobre os aspectos mnemônicos (psicológicos, portanto) que entram em jogo, quando da representação de determinadas propriedades espaciais através de atributos de cor determinados (azul para água; verde para terra).

A imediaticidade desta resposta é freqüentemente questionada nos debates acerca do aparente compartilhamento de "natureza" $e$ "convencionalidade" em artificios representacionais e na interpretação das imagens. É minha impressão que muitas linhas tendem a se cruzar nestas discussões, como quando se alega que aqueles que nunca viram fotografias não podem decodificá-las ou lê-las. As evidências acerca deste fato são conflitantes, mas qualquer que seja a verdade de determinadas anedotas, poder-se-ia igualmente interrogar se qualquer dificuldade é experimentada no reconhecimento de, por exemplo, animais de brinquedo feitos de madeira ou desenhos esquemáticos de objetos familiares, particularmente de propriedades dotadas de significação cultural e psicológica imediatas." 
Numa boa medida, podemos considerar que o dialogo entre Eco e Gombrich sumaria duas das grandes linhagens em que uma interrogação semiótica acerca da representação visual se encontra vertida: na primeira delas, encontramos a argumentação sobre o convencionalismo de base da representação pictórica, como uma declarada preferência (própria ao campo das teorias semióticas) pela idéia de conformar a questão do iconismo no âmbito das determinações que a semelhança visual sofre (sobretudo no plano da representação), desde um sistema simbólico especial, donde poderíanos aferir a tese de que a questão da similaridade decorre da caracterização que possamos fazer de um código iconográfico.

Se nos restituirmos ao argumento de Gombrich, logo no primeiro capitulo de Art and Illusion, veremos como é que a questão da construtividade artística dos efeitos de semelhança se põe, como exemplo da predominância deste aspecto convencionalista de uma tese semiótica: considerando o problema da representação naturalista de paisagens, na obra de John Constable, especialmente em um quadro que retrata a paisagem que um parque, em Sussex ("Wivanhoe Park", 1816), Gombrich se interroga sobre um modo comum de apreciar o efeito ilusionista da representação, que consiste em supor que esta veicule automaticamente as características sensiveis que seu autor houvera percebido imediatamente no modelo ou na paisagem.

O período em que este quadro foi produzido corresponde a uma fase da obra de Constable na qual os problemas do estilo da representação naturalista são cada vez mais assumidos como uma questão de filosofia natural: com isto, devemos considerar que o quadro não preserva as propriedades dos objetos da percepção, como um mero decalque pictórico da realidade, mas como uma experiência de reconstrução do mundo visual no plano de projeções pictórico, em escala reduzida, sendo assim parte de uma estratégia de convocação do apreciador aos marcos estruturantes de uma experiência sensivel de primeira ordem.

Mesmo que tomássemos a fotografia em preto-e-branco do mesmo parque, como um exemplo de um perfeito simile daquilo que percebemos, como dado dos sentidos, teríamos que reconhecer que, nem mesmo no registro, podemos supor uma integral reprodução, por exemplo, da variedade de tons percebidos pelo fotógrafo: no lugar de uma réplica do mundo visual, temos (do mesmo modo que na pintura) uma delinitação do mundo visivel, nos limites reduzidos do plano visual, assim como, do ponto de vista plástico, gradações limitadas na faixa dos cinzas. Se considerarmos, por outro lado, questões de escala e de distâncias focais, ainda assim o que se preserva na fotografia são sempre escolhas viabilizadas tecnicamente pelo aparelho.

Deveríamos concluir, nesta parte da argumentação gombricheana, que a questão da suposta semelhança entre representação e visão se encontraria muitas vezes delimitada e reduzida às características do meio escolhido para 
reproduzi-las: mais uma vez, temos o reforço de um viés que restringe o problema do esquematismo da representação aos meios materiais para a consecução dos efeitos plásticos. Este problema se torna muito evidente, quando Gombrich considera o modo como Constable trabalha diferentes aspectos da mesma paisagem, apenas por adotar técnicas e materiais distintos:

Em um deles, ele (Constable) parece ter usado um lápis de ponta muito dura. Teve então de ajustar todas as suas gradações ao que é, objetivamente uma gama muito exígua de tonalidades, que vai do cavalo preto no primeiro plano até as árvores distantes, através das quais parece brilhar a luz do céu, representada pelo papel acinzentado. Num desenho posterior, ele empregou um meio mais escuro e mais cru que lhe permitiu um contraste mais vigoroso e eficaz. Mas o que chamamos de 'contraste' aqui é, a rigor, uma gradação muito pequena na intensidade da luz refletida de diferentes áreas do desenho. Constable representou a mesma vista num esboço a óleo, hoje em Oxford, no qual as gradações de tom traduzem-se em áreas coloridas. Reproduz, então, o que o artista tinha diante dos olhos? ${ }^{12}$

Mas, se tratarmos a questão da semelhança icônica numa perspectiva mais próxima à manifestação sensível das formas deste discurso visual, a suposição de que estejamos constritos por uma estrita codicidade iconográfica não chegará a resolver a questão da dimensão propriamente perceptiva do fenômeno: as visões de Gombrich acerca do iconismo prenunciam uma perspectiva (de todo, intocada pela maior parte das abordagens semiótica e comunicacionais), na qual a questão da similaridade no plano visual não poderia se restringir ao patamar exclusivamente produtivo dos efeitos figurativos.

Ao não se permitir prescindir de um tratamento da experiência estética, na sua dimensão propriamente perceptiva de manifestação, Gombrich nos convida a apreciar um argumento (originário da psicologia da percepção) sobre a estrutura de base das atribuições de sentido para as representações visuais: a origem deste argumento nos conduz ao lugar das tensões entre o campo visual das projeções (restrito ao plano da representação) e a virtual indeterminabilidade e mutabilidade de formas no mundo visual, tomado enquanto matriz da experiência perceptiva, da qual as representações são, segundo Gombrich, um "experimento em redução". ${ }^{3}$

Nas duas últimas partes de Art and Illusion, observarmos o compromisso de Gombrich com uma tese sobre os princípios de uma cooperação perceptiva, como fenômeno de base de seu argumento psicológico sobre a interpretação da semelhança nas representações pictóricas: ele retoma o problema das projeções perceptivas, tão especialmente caro ao ramo mais experimental da 
psicanálise (especialmente, com os testes de Roschach), para caracterizar a hipotética precedência de uma faculdade imitativa, originária da apreciação de obras de pintura e de desenho; Gombrich desenvolve este tema psicológico na perspectiva mais avançada de um discurso sobre as possibilidades configuradoras da atividade receptiva; em recurso à psicologia de William James, caracteriza uma espécie de função cooperativa da percepção e da memória na complementação dos traços que definirão a representação reconhecida enquanto tal.

Sob este aspecto especifico (a saber, o de um apelo às estruturas perceptivas da compreensão das representações visuais), estas teses de Gombrich trazem sugestivas indicações das proximidades que se podem estabelecer entre as abordagens semióticas e estéticas, no trato com a questão do significado figurativo. No caso das teses de Eco, estamos nos reportando, evidentemente ao capitulo mais fortemente hermenêutico de sua teoria semiótica, aquele no qual encontramos o problema da interpretação, como um procedimento de abertura do texto para um horizonte de possibilidades, e que é firmado pela atividade mesma da interpretação do texto narrativo.

Estes são os temas mais caros à idéia, tantas vezes mal-apropriada, de obra aberta, especialmente na fase inicial das abordagens de uma estética da interpretação, em Umberto Eco: estas teses nada mais são que um prosseguimento das idéias pareysonianas da interpretação estética como instância formativa do sentido propriamente existencial da obra de arte.

Mais que prenunciarem uma idéia de indeterminabilidade radical da experiência estética, este argumento apenas aguça a idéia central (mais clara, em Eco, apenas a partir de sua fase semiótica) de um núcleo empírico da atividade da interpretação, e que se oferece como a garantia metodológica dos percursos da leitura das obras textuais. Aplicada de início ao problema da cooperação interpretativa nos textos narrativos, sentimos que as idéias de Gombrich sobre a completação do efeito estético, pela atividade do espectador são claramente uma fonte inspiradora para o percurso de Eco. ${ }^{14}$

No fundo destas mesmas teses, podemos igualmente rastrear as principais linhagens do discurso estético contemporâneo, sobretudo as vertentes originarias das teorias da formatividade, de um lado, e aquelas que caracterizam a escola das estéticas da recepção, de outro. Pois há também aqueles que se permitem encontrar os pontos de conexão entre as aproximações gombricheanas ao problema da atividade do espectador (e o argumento psicológico de base que ele parece implicar), e algumas das chaves que caracterizam, por sua vez, o mođo de aproximação dos autores vinculados à teoria literária da escola de Konstanz, que privilegia o papel da leitura na consecução do efeito estético da obra de arte, especialmente na letra de Wolfgang Iser. 
Também neste aspecto, podemos estabelecer que o lugar das interrogações estéticas de Gombrich é um ponto de interferência de algumas das questões mais caras ao campo disciplinar da estética contemporânea, na medida em que o problema da determinação do sentido ultimo da experiência estética parece chamar em causa o caráter fundante e estruturante da atividade da interpretação e da leitura das obras.

Pois aqui, como no caso da abordagem semiótica de Eco, nos defrontamos com uma suposta indeterminabilidade ou inefabilidade (em termos, com a abertura) do sentido na experiência estética, mas também instados a pensar que, os percursos de leitura e interpretação, deixam marcas sobre estas obras, na mesma medida em que também prosseguem instruções que estão supostamente já marcadas originariamente nas mesmas.

É tentador comparar estas teses sobre a indeterminação da imagem com as teses de Iser sobre o ato de leitura. Ainda que esta proximidade requeira um maior exame, há pouca dúvida sobre o fato de que a estética da recepção de Iser foi inspirada e influenciada pelo argumento de Arte e Ilusão. Por exemplo, os três requerimentos básicos da função da imagem que Gombrich avança, isto é, a equivalência, os meios e o preparo mental correspondem quase que integralmente àqueles que são requisitados no ato da leitura, por Iser. Assim, a equivalência corresponde ao repertório, os meios às estratégias e o preparo mental à disposição para a realização. ${ }^{\prime s}$

De fato, ao questionar os mitos pigmaliônicos sobre a geração do efeito ilusionista, ex-nihilo, Gombrich fala com muita propriedade sobre o papel exercido por um sistema de expectativas, originário da percepção, como elemento modular das relações, de natureza muitas vezes indutiva, e que se estabelecem entre $o$ ato produtivo da figuração e o lugar constitutivo da visão, não apenas como completação dos efeitos plásticos no plano de obras singulares, mas como um princípio estruturante da compreensão estética da composição enquanto texto.

A ilustração deste fenômeno de compreensão visual dos efeitos plásticos da representação nos é oferecida, por Gombrich, a partir do episódio de um pintor grego, Parrásio, que engana um seu colega, Zêuxis, por levá-lo a supor que uma cortina, posta sobre um de seus quadros devesse ser removida, para a melhor apreciação da obra (o pintor descobre, ao tentar removê-la, com assombro, que ela é parte integrante do próprio quadro). Esta narrativa implicaria numa visão sobre o sucesso da figuração como relativo ao papel que a percepção exerce no reforço das habilidades propriamente criativas.

À luz imparcial da razão, a proeza de Parrásio parece menos admirável. Na experiência do pobre Zêuxis, a possibilidade de 
uma cortina ser pintada era seguramente nula. Um leve jogo de luz e sombra deve ter bastado para fazer com que ele visse a esperada cortina, principalmente porque estava pensando na fase seguinte, na pintura que ia descobrir: Os pintores do trompe l'oeil têm se baseado desde então neste mútuo reforço da ilusão e da expectativa: a mosca pintada na tela, as cartas pintadas na caixa do correio. ${ }^{16}$

Isto é, a partir de Gombrich, devemos considerar que as questões ligadas à representação visual e à sua plasticidade deverão fazer apelo ao capítulo perceptivo da semelhança icônica, na contraparte das considerações acerca da realização produtiva (ou artistica) desta semelhança, que predominam, por sua vez, na semiótica e nas teorias da comunicação. E, de modo a não concluirmos que uma tal perspectiva, oriunda das abordagens psicológicas acerca da representação, pudessem prescindir das resultantes propriamente expressionais do significado icônico, nunca é demais lembrar que, em vários momentos de toda a sua extensa obra, Gombrich tem suscitado uma especial atenção à complementaridade com que esta abordagem pode acessar o complexo das representações visuais. ${ }^{17}$

Ao considerar a real localização da origem deste fenômeno cooperativo, Gombrich relembra que as projeções constituiam um método característico (sobretudo ilustrado pelas instruções de Leonardo a seus seguidores, no Trattato della Pintura): a importância deste método criativo era ressaltada sobretudo pelo caráter das limitações originárias dos veículos da representação. Os critérios através dos quais julgamos a presença de entidades, de determinadas propriedades do espaço ou dos objetos, muitas vezes nada tem a ver com as características atuais da representação, sendo assim resultantes deste esforço da percepção em preencher as lacunas de uma figuração que nunca poderia ser completa, na perspectiva de sua ontogênese.

Ao considerar certos aspectos da correção visual de representações, Gombrich elabora um princípio (a que chama de "princípio do etc."), segundo o qual a percepção de determinados caracteres da representação decorre da capacidade, localizada na recepção, de atribuir aos percepta algo que a representação oferece apenas parcialmente: este princípio não é apenas operatório na arte moderna (afeita que está às cooperações advindas da recepção), mas também constitui uma demarcação fundamental para a arte clássica, especialmente quando consideramos a significação das técnicas de sfumatto, especialmente com Leonardo, e o papel que atribuem à atividade do espectador, para a consecução de seus efeitos.

Quando olhamos as árvores do Wivanhoe Park, de Constable, aceitamos na base da confiança as (árvores) que estão mais remotas. As que estão mais próximas são tão convincentes, tão 
articuladas, que os 'etc' pintados pelo artista nem entram em cogitação. Pois hoje demonstra-se que esta nossa tendência a tomar as coisas literalmente pode levar-nos a curiosas ilusões, em que a mente é induzida a antecipar-se aos fatos e a esperar a continuação de uma série que, afinal de contas, não é tão simples assim. $^{18}$

Neste ponto, devemos reconhecer que o problema da interpretação de imagens possui uma contraface ligada às estruturas psicológicas da experiência estética, que não pode, por sua vez, ser facilmente abstraída por um viés semiótico de leitura: em Gombrich, poderíamos multiplicar as remissões da questão de quais são mesmo os esquemas que empregamos para avaliar obras visuais enquanto complexos de sentido ou enquanto textos, para apenas chegarmos ao mesmo ponto, uma vez e sempre reiterado: o de que descobriríamos, no fundo desta mesma exploração será a inevitável restituição da compreensão estética aos marcos de uma psicologia da percepção. ${ }^{19}$

A importância do argumento sobre a significação pictórica, não obstante as disputas havidas em torno do mesmo, é a de exibir um determinado modo de acesso aos significados icônicos, a partir daquilo que constitui a substância originária de sua estruturação: se as posições de Eco e de Gombrich podem variar aqui (e, decerto, elas variarão fortemente, entre si, o que podemos verificar, com mais detalhes, mais adiante), este aspecto parece menos importante, quando o defrontamos com a urgência, expressa em ambas as 216 posições, em que haja uma melhor delimitação analítica do fenômeno do iconismo pictórico (e sobretudo, de sua importância, como chave metodológica, no acesso aos materiais icônicos, na perspectiva de um bom firmamento da análise do discurso visual, na pintura e na fotografia).

Devemos aprofundar os resultados desta discussão, agora numa sede propriamente analítica, e não mais puramente teórica ou especulativa: pois, decerto que, mesmo sustentadas sobre pressupostos teoricamente discutiveis, a influência e o relativo sucesso do estruturalismo semiológico nas teorias da comunicação decorreu precisamente do fato de que este foi capaz de auxiliar os estudos comunicacionais, por gerar para os mesmos operadores analíticos muito eficazes, ao menos do ponto de vista empírico.

Assim sendo, se as observações que lançamos sobre as linhas gerais de uma abordagem perceptualista dos significados visuais podem ter algum valor para este campo, é necessário que elas sejam capazes de gerar aquilo que a semiologia visual gerou para as ciências sociais, em geral, isto, é modos de interpretar ou ler as imagens. Este é o desafio que se nos propõe, por agora. 


\section{Bibliografia:}

BARTHES, Roland. Elementos de Semiologia (trad. José Paulo Paes e Izidoro Blikstein). São Paulo: Cultrix (1992);

BARTHES, Roland. L'Obvie et l'Obtus. Paris: Seuil (1992);

DUBOIS, Phillipe. L'Acte Photographique. Bruxelles: Labour (1983);

ECO, Umberto. La Struttura Assente. Milano: Bomipiani (1968);

$\mathrm{ECO}$, Umberto. "Introduction to a semiotic of iconic signs". In: Versus: quaderni di studi semiotici. 1:1 (1972): pp. 1, 15.

ECO, Umberto. "Réflexions à propôs di débat sur l'iconisme (1968-1998). In: Visio: revue de la Association Internationelle de Sémiotique Visuelle. 3:1 (1998): pp. 9,32;

GIBSON, James J. "The Information avaiable on pictures". In: Leonardo. 4 (1971): pp. 27,35;

GIBSON, James J. (1978). "The Ecological Approach to the Visual Perception of Pictures", in: Leonardo. 11 (1978): pp. 227, 235;

GOMBRICH, Emest. Art and Illusion: a study in the psychology of pictoral representation. New York: Princeton University Press (1960);

GOMBRICH, Emest. "'The Sky is the Limit': the vault of heaven and pictorial vision". In: The Image and the Eye: further studies in the psychology of pictorial representation. London: Phaidon (1982): pp. 162, 171;

KATO, Tetsuhiro. "Picture-reading? Gombrich and the hermeneutics of art". In: Aesthetics. 4 (1990): pp.

LOPES, Dominic. Understanding Pictures. Oxford: Clarendon Press (1996);

PICADO, José Benjamim. "O problema do iconismo: um dogma semiótico". In: De Signis. (a sair);

SCHAEFFER, Jean-Marie. L'Image Précaire: du dispositif photographique. Paris: Seuil(1987);

SONNESSON, Goran. Pictorial Concepts. Lund: Lund University Press (1989);

\section{Notas:}

'Barthes, Roland. "La Message photographique". In: L'Obvie et l'Obtus:essais criqtiques III. Paris: Seuil (1982): pp. 21.

${ }^{2} \mathrm{Cf}$. Goodman, Nelson. "Reality remade". In: Languages of Art: a study in the theory of symbols. Indiana: Hackett (1968). Os pontos que reiteramos sobre a avaliação crítica das perspectivas semiológicas constituem a base de nossa argumentação sobre os limites desta abordagem. Cf. Picado, José Benjamim. "Os Desafios Metodológicos da Leitura de Imagens: um exame crítico da semiologia visual". In: Fronteiras. 4:2 (2002): no prelo.

${ }^{3}$ Ao tratar da influência dos escritos sobre representação e semelhança perceptiva, especialmente nas obras de Ernest Gombrich, James J. Gibson e Richard Wollheim, alguns comentadores caracterizam as vertentes que insistem numa relação entre a compreensão das imagens visuais e as estruturas 
perceptivas de base, como sendo uma visão perceptualista da análise das imagens; em oposição a estas, poderíamos reconhecer a perspectiva das semióticas, que apostam numa espécie de vínculo gramatical entre os ícones e seus significados. Para reconhecer estas distinções, vide Lopes, Dominic. Understanding Pictures Oxford: Clarendon Press (1996).

${ }^{4}$ Gombrich, Ernest. "Análise da visão na arte". In Arte e Ilusão: um estudo da psicologia da representação pictórica (trad. Raul de São Barbosa). São Paulo: Martins Fontes (1995): p. 309

${ }^{5}$ Naquilo que a avaliação desta suspeita contra a semiologia implica numa consideração das posições semióticas de Umberto Eco, temos mantido igualmente uma posição de reserva crítica, sobretudo quando, para Eco, o estabelecimento dos saberes semióticos sobre a iconicidade prescindem daquilo que diz respeito às abordagens perceptualistas da significação visual, que buscamos propor enquanto chave para a interpretação das imagens. $O$ argumento de Eco está sistematizado na segunda parte da La Struttura Assente, mas também demarca suas sucessivas reavaliações do tema do iconismo e das mensagens visuais. Cf. "Introduction to a semiotic of iconic signs". In: Versus: quaderni di studi semiotici. 1:1 (1972): pp. 1, 15. Ver tb. "Réflexions à propôs di débat sur l'iconisme"(1968-1998). In: Visio. 3:1 (1998): pp. 9,32.Para uma avaliação mais intensiva das posições semióticas de Eco, ver Picado, José Benjamim. "O problema do iconismo: um dogma semiótico". In: De Signi. 3:1 (2003): pp. 61,74.

$218{ }^{6}$ De algum modo, é este também o problema de abordagem que justamente parecem partir da idéia de indexicalidade radical, para desenvolver um discurso sobre a significação da fotografia. Quer nos parecer que a questão da contigüidade factual entre o signo fotográfico e seu referente não deveria constituir um problema de base para a semiótica da fotografia; do ponto de vista de sua significação, a estrutura de funcionamento dos signos fotográficos permanece sendo aquela que aloja seus signos na condição de signos icônicos. Para avaliar a posição da indexicalidade de base do dispositivo fotográfico, vide Dubois, Phillipe. L'Acte Photographique. Bruxelles: Labour (1983). Na perspectiva mais próxima à iconicidade de base das imagens fotográficas, ver Scheffer, Jean-Louis. L'Image Précaire: du dispositif photographique. Paris: Seuil (1987).

${ }^{7}$ Cf. Eco, Umberto. A Estrutura Ausente, op.cit: p. 108.

8 "Ver significa capturar umas poucas propriedades destacadas do objeto: $\mathrm{o}$ azul do céu, a curva do pescoço do cisne, a retangularidade do livro, o brilho de um pedaço de metal, a estreiteza de um cigarro. Umas poucas linhas e pontos são prontamente aceitas como 'um rosto', não apenas por alguém que pertença à civilização ocidental, e que poderia suspeitar da existência de um acordo acerca de uma 'linguagem dos signos', mas também por crianças, selvagens e animais (...).Um caricaturista hábil pode suscitar esta semelhança, 
pelo emprego de linhas bem-escolhidas. Identificamos alguém conhecido, à distância, por observar não mais do que as mais elementares proporções ou movimentos". Cf. Arnheim, Rudolf. "Shape". In: Art and Visual Perception: a psychology of the creative eye. Berkeley: University of California Press (1974): pp. 43,44.

${ }^{9}$ A Estrutura Ausente, op.cit.: p. 110

${ }^{10} \mathrm{Cf}$. Eco, Umberto. "Introduction to a semiotics of iconic signs". In: Versus. 2:1 (1 972): p. 2. Vide tb. Gombrich, Ernest.

"Meditações sobre um cavalinho de pau ou as raizes da forma artística". In: Meditações Sobre um Cavalinho de Pau (trad. Geraldo Gerson de Souza). São Paulo: Edusp (1999): pp. 1,11

"Cf. Gombrich, Ernest. "Mirror and Map: theories of pictorial representation". In: The Image and the Eye: further studies in the psychology of pictorial representation. London: Phaidon (1982): pp. 185,186. As referências a um viés semiótico da abordagem de Gombrich ao problema da representação pictórica multiplicam-se em sua obra, desde as indicações mais remotas a uma abordagem convencionalista do efeito figurativo, até o ponto da problematização mais efetiva dos limites entre conceitos como os de "signos" e "imagens", para um campo como o da história da arte. Cf. Gombrich, Ernest. "Image and Code: scope and limits of conventionalism in pictorial representation". In: The Image and the Eye, op.cit.: pp. 278,298.

${ }^{12}$ Gombrich, Ernest. Arte e llusão, op.cit.: p. 39.

${ }^{13}$ Este argumento nos restitui não apenas às influências, mas os pontos de debate entre as idéias de Gombrich e as teorias da percepção pictórica, em James J. Gibson. Não é casual que Gombrich convoque ao corpo de sua argumentação as idéias de Gibson sobre a estruturação de um modo de percepção que já é pictórica na sua própria gênese: há todo um imenso campo de disputas, que certamente tem consequências para o debate semiótico acerca do iconismo, ao qual poderiamos fazer apelo, quando buscamos caracterizar uma abordagem perceptualista dos significados visuais. Trata-se da discussão na qual podemos encontrar entretidos os problemas de uma abordagem sobre os significados pictóricos, a partir de uma ecologia da representação visual (especialmente em torno das idéias de Gibson), e das reações que estas idéias suscitam, especialmente na teoria da figuração de Gombrich. Cf. Gibson, James J. (1971). "The Information avaiable on pictures". In: Leonardo. 4; Gibson, James J. (1978). "The Ecological Approach to the Visual Perception of Pictures", in: Leonardo. 11; Ver também as posições de Gombrich, em: " The Sky is the Limit': the vault of heaven and pictorial vision". In: The Inage and the Eye, op.cit: pp. 162, 171 . As sugestões de uma abordagem semiótica do iconismo já são bastante numerosas, especialmente no âmbito das teorias de uma retórica visual. Mas, muito especialmente fora das linhagens do estruturaliusmo semio-linguístico, 
chamamos especialmente a atenção sobre os escritos de Göran Sonnesson, que desenvolve uma abordagem semiótica do iconismo, a partir de uma abordagem ecológica, justamente influenciada pelas posições de Gibson. Cf. Sonnesson, Göran. Pictorial Concepts. Lund: Lund University Press (1989). ${ }^{14}$ Cf. Pareyson, Luigi. "Lettura, interpretazione e critica". In: Estetica:. Teoria della fromativitá. Milano: Bompiani (1954): pp. 219,272. Ver tb. Eco, Umberto. Opera Aperta: forma e indeterminazione nelle poetiche contemporanee. Milano: Bompiani (1962). Para avaliar a fase semiótica do problema da interpretação, vide: Eco, Umberto. Lector in fabula: la coperazione interpretativa nei testi narrativi. Milano: Bompiani (1979). A fase mais aguda do argumento semiótico sobre a interpretação encontra-se sumariada em Eco, Umberto. I Limiti delle Interpretazione. Milano: Bompiani (1990).

${ }^{15}$ Kato, Tetsuhiro. "Picture-Reading? Gombrich and the hermeneutics of art". In: Aesthetics. 4 (1990): p. 26.

${ }^{16}$ Gombrich, Arte e Ilusão, op.cit.: p. 216, 217.

${ }^{17}$ Cf. Gombrich, Ernest. "Expressão e Comunicação". In: Meditações Sobre um Cavalinho de Pau, op.cit.: pp. 56,69; Ver também, de Gombrich, "The Visual Image: its place in communication". In: The Image and the Eye, op.cit.: pp. 137,161. Sobre as relações entre o lugar das abordagens e estéticas e semiótica da representação visual, em Gombrich, ver: "Preface: images and signs". In: Art and Illusion. New York: Princeton University Press (2000). ${ }^{18}$ Gombrich, Arte e Ilusão, op.cit.: p. 230.

$220{ }^{19}$ É evidente que Gombrich explora este ponto, com mais riqueza do que a que ousamos apresentar até aqui: ao comparar, a partir dos exemplos das ambigüidades das formas visuais em Escher, a interpretação estética aos processos de leitura, vê-mo-lo ensaiando as mais sugestivas indicações de proximidade estrutural entre o trato receptivo com textos e representações, por supor que, em ambas, não operamos dedutivamente, a partir de formas abstratas transcendentes, mas por saltos indutivos, pelos quais formamos imagens sempre provisórias do todo composicional. "Lemos um quadro como lemos uma linha impressa, pegando as letras ou sugestões e juntando-as até sentirmos que olhamos, através dos signos da página, para o sentido que está por trás deles. E, assim como na leitura, o olho não viaja ao longo da linha a um mesmo ritmo juntando o significado de letra por letra e de palavra por palavra, assim como também nosso olhar varre uma pintura à procura de informação". Cf. Gombrich, Ernest. "Ilusão e impasse visual". In: Meditações sobre um Cavalinho e Pau e outros ensaios, op.cit: p. 155.

\section{Palavras-chave}
1. Imagens
2. Iconismos
3. Semiótica
4. Pictorialismo 